\title{
PENGEMBANGAN MODEL PEMBELAJARAN MATEMATIKA SMP KELAS VII BERBASIS KEHIDUPAN MASYARAKAT JAWARA (JAWA DAN MADURA) DI KABUPATEN JEMBER
}

\author{
Abi Suwito dan Dinawati Trapsilasiwi \\ Program Studi Pendidikan Matematika Universitas Negeri Jember \\ e-mail: Abi.fkip@unej.ac.id
}

\begin{abstract}
This research is meant to develop innovative teaching equipment which able to improve as well as conserve the culture through Mathematics learning. Learning equipment which is developed are in the form of students' book and LKS (Student's Work Book) of Mathematics subject of VIIth grade concerning with the culture of Javanese and Maduries who lives in Jember district. This developmental study is planned in three steos, namely; theorethical study and needs analysis, formulation of learning equipments, as well as testing the equipments and eksperiment. The Model used in this research is developmental model of ADDIE, which divided into 5 phases, namely; Analysing, Designing, Developing, Implementing and Evalualing. The subject of this research are three students of VII grade of SMP (Junior High School). The product of this research is students book which based on Javanese and Maduries culture. The result of this research shows that students' learning test in Squares subject based on Javanese and Maduries culture are good, with rate of 83,33. It can be conclude that students' book of VII SMP which based on Javanese and Maduries culture in Squares Shapes material are effective to be used in teaching.
\end{abstract}

Key words: Mathematics Learning, Javanese culture, Maduries Culture

\begin{abstract}
Abstrak : Penelitian ini bertujuan untuk mengembangkan perangkat pembelajaran inovatif yang dapat menumbuhkan dan melestarikan budaya melalui pembelajaran matematika. Perangkat pembelajaran yang dikembangkan berupa buku siswa dan LKS mata pelajaran Matematika kelas VII yang dikaitkan dengan budaya masyarakat Jawa Dan Madura yang ada di kabupaten Jember. Penelitian pengembangan ini direncanakan berlangsung dalam tiga tahap. Pertama, kajian teori dan analisis kebutuhan. Kedua, perumusan perangkat pembelajaran sesuai dengan hasil analisis kebutuhan. Ketiga, uji coba perangkat dan eksperimen. Pada penelitian ini model yang digunakan adalah model pengembangan ADDIE, yang terbagi dalam 5 fase, yaitu: 1) Fase Analisis, 2) Fase Desain, 3) Fase Development, 4) Fase Implementasi 5) Fase Evaluasi. Subyek penelitian adalah siswa kelas VII SMP sebanyak 3 orang. Produk pada penelitian ini yaitu buku siswa yang berbasis budaya Jawa dan Madura. Hasil penelitian menunjukkan bahwa, tes belajar siswa materi keluarga segi empat berdasarkan budaya Jawa dan Madura, baik, dengan rerata 83,33. Dapat disimpulkan bahwa buku siswa kelas VII SMP berbasis budaya Jawa dan Madura pada materi segiempat efektif digunakan untuk pembelajaran.
\end{abstract}

Kata Kunci : Pembelajaran Matematika, Kebudayaan Jawa, dan Madura

\section{PENDAHULUAN}

Pengaruh globalisasi yang masuk ke negeri kita memberikan dampak positif bagi generasi penerus bangsa kita. Namun tidak dipungkiri juga memberikan dampak negatif, yaitu merosotnya nilai-nilai budaya lokal. Tergesernya budaya lokal dapat diindika- sikan dengan perubahan cara pergaulan yang berkiblat pada budaya asing. Salah satu contoh nyata yang dapat dilihat yaitu menjamurnya permainan canggih, misalnya playstation yang menggeser budaya lokal warisan nenek moyang. Selain itu, banyaknya tayangan hiburan di televisi yang 
kurang mendidik generasi penerus. Acara televisi yang menggali nilai-nilai budaya atau melestarikan budaya lokal tidak pernah ditayangkan.

Konsekuensi dari kondisi ini akan melunturkan nilai-nilai sosial dan kekeluargaan yang digantikan dengan sifat-sifat individual dikalangan generasi muda. Selain itu, ketertarikan terhadap tayangan hiburan asing di media elektronik tentunya menjadi faktor lain yang dapat melunturkan pemahaman dan pengenalan mereka terhadap budaya lokal. Untuk itu perlu adanya penanganan yang efektif untuk mengatasi permasalahan ini. Sesuai yang diamanatkan dari UUD 1945 pasal 32 menyatakan bahwa "Negara memajukan kebudayaan nasional Indonesia di tengah peradaban dunia dengan menjamin kebebasan masyarakat dalam memelihara dan mengembangkan nilai-nilai kebudayaannya." Pasal tersebut mengisyaratkan untuk memelihara dan mengembangkan kebudayaan nasional Indonesia dengan berbagai cara bagi setiap warga negara. Salah satu cara sebagai tindak lanjut dari amanat dalam pasal 32 tersebut adalah pada jalur pendidikan dapat melestarikan dan mengembangkan kebudayaan sebagai bagian dari kebudayaan nasional Indonesia.

Pemerintah melalui Kemendikbud telah berupaya melestarikan kebudayaan lokal di setiap daerah melalui jalur pendidikan, yaitu dengan menyisipkan mata pelajaran yang berkaitan dengan budaya, seperti mata pelajaran seni budaya dan kesenian. Alokasi waktu untuk mata pelajaran tersebut masih terlalu sedikit bila dibandingkan dengan mata pelajaran lainnya, sehingga kurang efektif jika ingin menanamkan budaya pada mata pelajaran tersebut. Untuk itu perlu strategi yang efektif, yaitu menyisipkan budaya dalam mata pelajaran yang memiliki alokasi waktu yang banyak dalam pembelajaran di sekolah. Salah satu mata pelajaran yang memiliki alokasi waktu yang besar adalah matematika. Dengan demikian, salah satu cara efektif untuk melestarikan budaya adalah melalui pembelajaran matematika berbasis budaya.

Pembelajaran matematika berbasis budaya atau lebih dikenal dengan istilah Etnomatematika, pertama kali dicetuskan dan dikembangkan oleh seorang matematikawan Brasil yaitu Ubiratan D'Ambrosio. Menurut D'Ambrosio, etnomatematika adalah suatu studi tentang pola hidup, kebiasaan atau adat istiadat dari suatu masyarakat di suatu tempat yang memiliki kaitan dengan konsep-konsep matematika namun tidak disadari sebagai bagian dari matematika oleh masyarakat tersebut. Sejak pertama kali dicetuskan hingga saat ini, etnomatematika telah berkembang di berbagai belahan dunia dan mengalami kemajuan pesat karena memberi pengaruh positif bagi perkembangan budaya dan pendidikan matematika. Pada penelitian ini yang menjadi sasaran yaitu masyarakat Jember,karena terdapat suku Jawa dan Madura. Suku Jawa-Madura (Jawara) menetap di bagian timur, yaitu di bagian pulau Jawa sebelah utara, yang menghadap langsung Pulau Madura. Titik pusat wilayahnya adalah Kabupaten Jember dan sekitarnya. Ada beberapa masyarakat Jawa dan Madura yang ada di Kabupaten Jember yaitu orang Jawa yang dibesarkan di kampung-kampung Madura sehingga bahasa sehari-hari adalah bahasa ngoko Jawa yang dipakai dengan kerabatnya orang Jawa dan atau orang Madura yang hidup bercampur di sana, dan Orang Jawa "pendalungan", yaitu orang Jawa keturunan pasangan JawaMadura.

Kehidupan ekonomi orang Jawara umumnya berlangsung di perkebunan dan peternakan. Selain itu mereka bekerja sebagai saudagar, pengrajin kayu dan batik, dan 
berbagai profesi lainnya. Orang Jawara pedesaan umumnya tinggal di rumah gedek dengan lantai masih tanah, sedangkan di kota, corak rumahnya modern, pakai tembok sesuai perkembangan jaman. Pakaiannya cenderung berwarna menyolok dan lebih terbuka.

Kenyataan yang terjadi di sekolah, sebagian besar guru masih belum bisa mengkaitkan mata pelajaran matematika dengan budaya lokal yang ada. Mereka masih menganggap mata pelajaran satu dengan yang lain belum bisa dikaitkan. istilah pada kurikulum 2013 yaitu tematik integratif. Matematika merupakan salah satu mata pelajaran yang ada pada setiap jenjang pendidikan. Paradigma yang berkembang di masyarakat tentang pelajaran matematika merupakan pelajaran yang menakutkan dan membosankan adalah suatu hal yang cukup beralasan. Yansen Marpaung (2003:1) mengungkapkan "pendidikan matematika kita selama ini tidak berhasil meningkatkan pemahaman matematika yang baik pada siswa, tetapi berhasil menumbuhkan perasaan takut, persepsi terhadap matematika sebagai ilmu yang sukar dikuasai, tidak bermakna, membosankan, menyebabkan stres pada diri siswa". Ungkapan tersebut merupakan indikasi bahwa siswa belum dapat diubah ranah afektif dan kognitifnya untuk menjadi lebih baik.

Kenyataan kualitas pendidikan matematika yang masih jauh dari harapan tersebut ternyata dibarengi dengan aktivitas siswa yang kurang terlibat aktif dalam proses pembelajaran matematika. Pada tahap pengembangan kegiatan inti pembelajaran, ketika penyajian konsep dan demonstarsi keterampilan matematis melalui pembahasan contoh soal, hanya segelintir siswa saja yang dapat diajak berkomunikasi, dalam arti dapat menjawab pertanyaan atau mengajukan pertanyaan. Sebagian besar siswa takut mengemukakan pendapat atau gagasan di hadapan guru, padahal guru sudah membuka kesempatan untuk bertanya, menjawab atau memberi tanggapan atas penjelasan yang sudah disampaikan. Dengan kata lain, antara guru dan siswa seolah-olah terdapat hambatan psikologis yang menghalangi siswa untuk belajar secara aktif. Selanjutnya pada tahap penerapan, ketika tiba saatnya untuk menggunakan konsep, aturan dan rumus dalam menyelesaikan soal, banyak siswa yang hanya menyontek pekerjaan temannya tanpa mau berpikir sedikitpun atau menanyakan bagaimana proses memperoleh jawaban pada penyelesaian soal. Demikian pula saat ulangan atau ujian, siswa tampak kurang percaya pada kemampuannya sendiri dalam menyelesaikan soal. Berdasarkan fakta tersebut dapat disimpulkan bahwa prestasi dan aktivitas belajar matematika anak Indonesia masih sangat rendah.

Sejalan dengan paradigma baru pendidikan di Indonesia yang lebih menekankan pada peserta didik sebagai manusia yang memiliki potensi untuk belajar dan berkembang, pemerintah mendorong pelaksanaan pembelajaran pada jenjang pendidikan dasar dan menengah yang berorientasi pada PAKEM. Depdiknas (2005:68) menyatakan pembelajaran yang berorientasi pada PAKEM adalah pembelajaran yang dirancang agar mengaktifkan anak mengembangkan kreatifitas sehingga efektif namun tetap menyenangkan.

Diharapkan dengan menerapkan pembelajaran PAKEM pada pembelajaran matematika, yaitu dengan menyisipkan budaya lokal, akan membuat peserta didik dapat mengikuti pembelajaran dengan baik serta diharapkan dapat memotivasi belajar siswa dikelas sehingga dapat mengaktifkannya. Selain juga dapat mengembangkan melestarikan budaya lokal. 


\section{METODE}

\section{Subjek Penelitian}

Data dalam penelitian ini terbagi atas tiga kategori, yakni data verbal, data berupa perilaku, dan data berupa skor atau nilai siswa. Data verbal berupa informasi tertulis tentang kegiatan masyarakat yang menggunakan kegiatan matematika. Berbagai informasi tertulis tersebut digunakan sebagai dasar dalam merumuskan perangkat pembelajaran etnomatematika. Data berupa perilaku guru dan siswa diperoleh dari hasil observasi terhadap pembelajaran dengan menggunakan perangkat pembelajaran yang digunakan. Data berupa perilaku ini dianalisis untuk memperoleh gambaran tentang proses pembelajaran serta aktivitas siswa dan guru. Sementara itu, data skor atau nilai siswa digunakan untuk mengetahui kualitas hasil belajar serta efektivitas perangkat pembelajaran

Siswa yang menjadi sumber data adalah siswa kelas VII dari sekolah di Kabupaten Jember. Dari sumber data ini akan diperoleh data berupa perilaku dalam kegiatan pembelajaranskor hasil tes. Adapun guru yang menjadi sumber data adalah guru kelas VII di Kabupaten Jember.

\section{Prosedur Penelitian}

Tempat penelitian adalah Kabupaten Jember yang ditempati suku Jawa dan Madura dan Program Studi Pendidikan Matematika FKIP Universitas Jember. Dengan subjek penelitian adalah masyarakat Jawa dan Madura yang berdiam di/berdomisili di Kabupaten Jember.

Instrumen pengumpul data pada penelitian ini terdiri atas perangkat pembelajaran yang akan dikembangkan berupa buku guru, buku siswa dan LKS, lembar pengamatan aktivitas masyarakat Jawa dan Madura, Soal Tes dan Angket

Penelitian ini dimaksudkan untuk mengembangkan perangkat pembelajaran sebagai produk penelitian. Penelitian yang digunakan adalah desain penelitian dan pengembangan (Research and Development) yang sering disebut penelitian pengembangan. Hal ini sesuai dengan pendapat Sugiono (2010) yang menyatakan bahwa penelitian yang menghasilkan produk tertentu dan menguji keefektifan produk tersebut termasuk penelitian pengembangan.

Untuk diperoleh produk pengembangan yang baik, perlu ditempuh suatu prosedur tertentu, yakni mengacu pada model pengembangan. Pada penelitian ini model yang digunakan untuk pengembangan bahan ajar yang diakitkan dengan kegiatan masyarakat Jawa dan Madura adalah model pengembangan ADDIE. Model pengembangan ADDIE merupakan suatu model dalam mendesain suatu perangkat pendidikan yang terbagi dalam 5 fase, yaitu:1) Fase Analisis, 2) Fase Desain, 3) Fase Pengembangan, 4) Fase Implementasi 5) Fase Evaluasi.

Pengembangan perangkat pembelajaran etnomatematikaini meliputi kegiatan penulisan prototype buku guru, buku siswa dan LKS, perangkat pembelajaran serta instrumen penelitian, review (ahli dan praktisi), revisi, uji coba dan revisi akhir. Review dilakukan oleh tiga orang ahli yang memiliki kompetensi di bidang geometri analitik ruang dan tiga orang pendidik untuk mendapatkan masukan sebagai bahan perbaikan sebelum prototype modul pembelajaran, perangkat pembelajaran serta instrument penelitian diujicobakan. Uji coba dilakukan pada peserta didik kelas VII di Kabupaten Jember. Uji coba dimaksudkan untuk mendapatkan masukan dari lapangan, untuk bahan perbaikan.

Uji coba akan dilakukan dalam dua tahap yaitu: 1) Uji coba kelompok kecil; Uji coba kelompok kecil termasuk validasi empirik terhadap produk. Uji coba ini dilakukan terhadap empat siswa kelas VII di Kabupaten Jember yang memiliki ke- 
mampuan yang bervariasi (tinggi, sedang dan rendah). 2) Uji coba lapangan; Uji coba lapangan akan dilakukan pada siswa kelas VII di Kabupaten Jember secara klasikal.

\section{HASIL DAN PEMBAHASAN}

Dari hasil validasi buku siswa dan tes hasil belajar, dua validator mengatakan valid. Hasil dari pengerjaan LKS adalah sebagai berikut:

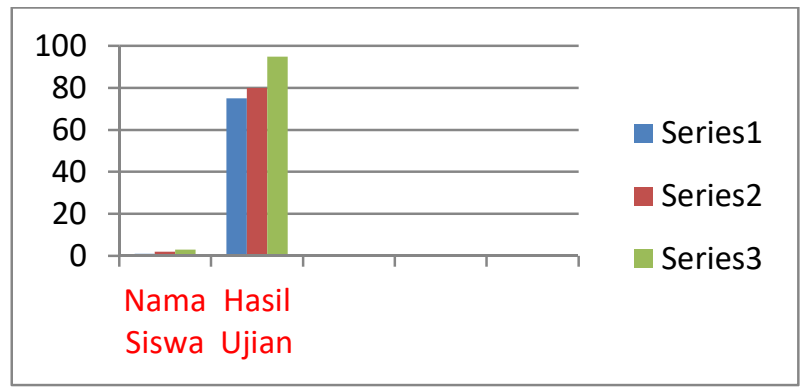

Gambar 1. Diagram Hasil Penilaian LKS

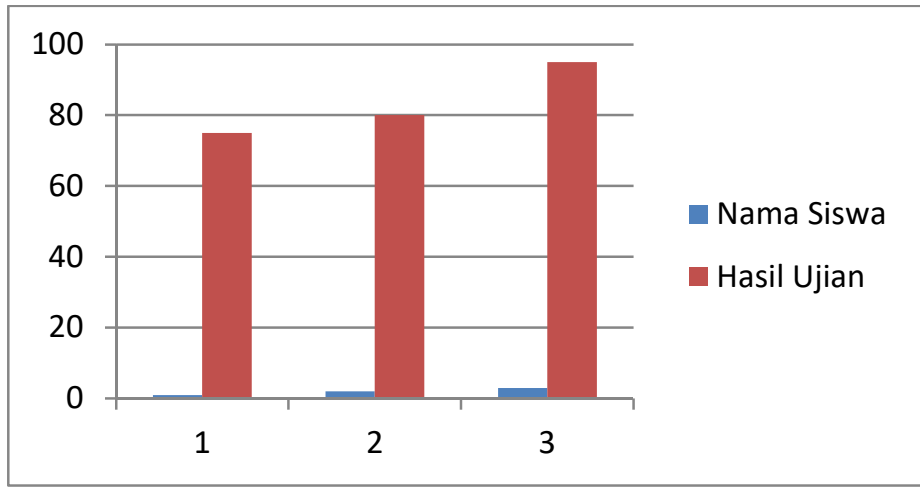

Gambar 2 Hasil Tes Belajar Siswa Materi Keluarga Segiempat

Dari diagram 1 dan 2 tampak bahwa hasil pengerjaan LKS dan hasil ujian menunjukkan bahwa hasilnya baik. Dari hasil pengamatan selama kegiatan pembelajaran berlangsung, tampak siswa mendapatkan suasana yang agak berbeda dengan yang mereka dapatkan sebelumnya. Pembelajaran bernuansa budaya daerah Jawa dan Madura. Siswa dibawa dalam suasana dalam kehidupan sehari-hari mereka yang diharapkan dapat memotivasi belajar dengan lebih bersemangat sehingga mendapatkan hasil belajar yang sesuai dengan harapan, hal ini sesuai dengan pendapat Aitken.

Hasil ujian yang baik, mengindikasikan bahwa dengan diterapkannya pembelajaran berdasarkan budaya dapat membuat siswa lebih bersemangat dalam belajar. Siswa tidak hanya menghafal rumus, mengerjakan sesuai prosedur tetapi lebih dikenalkan pada budaya sekitar.

Berdasarkan hasil penelitian juga diketahui bahwa pembelajaran berdasarkan budaya efektif meningkatkan hasil belajar siswa. Selama implementasi pembelajaran siswa juga dibiasakan dengan bekerja sama dengan mahasiswa lain, berpartisipasi dalam bekerja kelompok, memiliki tanggung jawab terhadap kelompoknya yang sesuai dengan pendapat Rusfeendi bahwa siswa memiliki kepercayaan diri yang tinggi karena ingin mendapatkan nilai yang baik. 


\section{SIMPULAN}

Dari hasil penelitian dan pembahasan, maka dapat dipaparkan simpulan hasil penelitian ini adalah model pembelajaran berdasarkan budaya Jawa dan Madura (etnomatematika) menunjukkan hasil yang

\section{DAFTAR PUSTAKA}

Darhim. (2004. Pengaruh Pembelajaran Matematika Kontekstual terhadap Hasil belajar Matematika Siswa Sekolah Dasar.Disertasi UPI: Tidak diterbitkan

Depdiknas. 2006. Kurikulum Tingkat Satuan Pendidikan (KTSP). Jakarta: Depdiknas.

Herdian. (2010). Pengaruh Metode Discovery terhadap Kemampuam Analogi dan Generalisasi Matematis Siswa SMP. Tesis UPI: Tidak diterbitkan

Hobri. 2010. Metodologi Penelitian Pengembangan (Aplikasi pada Penelitian Pendidikan Matematika). Jember: Pena Salsabila.

Kusmaryono, Imam. 2012. Pengembangan Pembelajaran Matematika Kontekstual Edutainment Berbasis Budaya Lokal di Daerah. Disajikan Seminar Kemendikbud Dikti 25-27 September 2012 "Designing Quality Learning Landscape in Indonesia".

Ma, X. (1997). "Assessing The Relationship Between Attitude Toward Mathematics and Achievement in Mathematics: A Meta-Analysis". Journal for Research in Mathematics Education, 28 (1), 26-47.

Prasetya, J; dkk. 2004. Ilmu Budaya Dasar. Jakarta: Rineka Cipta.

Powell, A. B \& Frankenstein, M. Ethnomathematics: Challenging Eurocentrism in Mathematics Education. United States of America: Diane Ganeles. sangat positif, yang diindikasikan adanya hasil pengerjaan LKS yang baik dan hasil tes yang baik pada materi keluarga segiempat dan dengan pembelajaran ini juga mampu meningkatkan kemampuan siswa dalam mempresentasikan hasil karyanya.

Rosa, M. \& Orey, D. C. 2011. Ethnomathematics: The Culture Aspek of Mathematics. Revista Latinoamericana de Etnomatematica, 4(2): 32-54.

Ruseffendi, H. E. T. (1986). A Comparison of Participation in Mathematics of Male and Female Students in the Transition From Junior to Senior High School in West Java-Indonesia. Disertasi. Ohio: The Ohio State University. .(1991). Pengantar kepada Membantu Guru Mengembangkan Kompetensinya dalam Pengajaran Matematika untuk Meningkatkan CBSA. Bandung: Tarsito

Sugiono, 2010. Metode Penelitian Pendidikan. Bandung: Alfabeta.

Soelaeman, M. 2010. Ilmu Budaya Dasar. Bandung: Refika Aditama.

Tandililing, Edy. 2013. Pengembangan Pembelajaran Matematika Sekolah Dengan Pendekatan Etnomatematika Berbasis Budaya Lokal Sebagai Upaya Untuk Meningkatkan Kualitas Pembelajaran Matematika Di Sekolah, Makalah dipresentasikan dalam Seminar Nasional Matematika dan Pendidikan Matematika dengan tema "Penguatan Peran Matematika dan Pendidikan Matematika untuk Indonesia yang Lebih Baik" pada tanggal 9 November 2013 di Jurusan Pendidikan Matematika FMIPA UNY, P25 . 
